\title{
Current state of social media utilization in neurosurgery amongst European Association of Neurosurgical Societies (EANS) member countries
}

\author{
Aria Nouri ${ }^{1} @$. Julien Haemmerli ${ }^{1}$ - Alexandre Lavé ${ }^{1}$ Pia Vayssiere ${ }^{1}$. Paul Constanthin ${ }^{1}$ - Abdullah Al-Awadhi ${ }^{2}$. \\ Gregory Zegarek ${ }^{1} \cdot$ Insa Janssen ${ }^{1} \cdot$ Hans Clusmann ${ }^{3} \cdot$ Christian F. Freyschlag $^{4} \cdot$ Johannes Goldberg $^{5}$. \\ Marcus Czabanka ${ }^{6} \cdot$ Martin N. Stienen $^{7}$. Philippe Bijlenga ${ }^{1,2} \cdot$ Karl Schaller $^{1,2}$
}

Received: 30 December 2020 / Accepted: 28 June 2021 / Published online: 27 July 2021

(c) The Author(s) 2021

\begin{abstract}
Background Social Media (SoMe) is becoming increasingly used in the medical community, and its use has been related with academic productivity. However, utilization of SoMe in the European neurosurgical community has not been assessed systematically.

Methods An online search was undertaken to discover SoMe accounts of (1) national and related neurosurgical societies listed on the EANS website, (2) neurosurgical journals present on EANS website, (3) neurosurgery centers within EANS member countries, as listed on their website. SoMe accounts of Facebook, Twitter, YouTube, and Instagram were searched for journals and societies, and Twitter, Instagram, and Facebook for neurosurgery departments. The number of likes/followers/subscribers was recorded.

Results Five (31\%) neurosurgery journals had a SoMe presence. The highest number of followers, likes, and tweets was found for JNNP, and Journal of Neurological Surgery Part B had the most subscribers and video views. SoMe usage was identified for 11 national (28.2\%) and 2 multi-national neurosurgical societies. From these, the French Society of Neurosurgery had the largest number of Facebook followers $(>2800)$ and Likes $(>2700)$, the Society of British Neurological Surgeons had the largest number of Twitter followers ( $>2850$ ), whereas EANS overall had the most followers on Twitter $>5100$ and Facebook $>5450$. A total of 87 SoMe neurosurgery center accounts were found on either Facebook, Instagram or Twitter, for 64 of 1000 centers $(6.4 \%)$ in 22 of 40 different countries $(55 \%)$. Of these $67 \%(n=43 / 64)$ arose from 6 countries (England, Germany, Italy, Romania, Turkey, Ukraine). There were more Facebook accounts $(n=42)$ than Instagram accounts $(n=23)$ or Twitter accounts $(n=22)$.

Conclusion SoMe use amongst neurosurgical societies and departments in Europe is very limited. From our perspective, explanations are lacking for the correlated numbers to the market shares of SoMe in the respective countries. Further research, including a survey, to follow up on this important topic should be undertaken among EANS members.
\end{abstract}

Keywords Twitter $\cdot$ Instagram $\cdot$ Facebook $\cdot$ Followers $\cdot$ Public engagement $\cdot$ Social media $($ SoMe) $\cdot$ YouTube $\cdot$ LinkedIn

This article is part of the Topical Collection on Neurosurgery

Training

Aria Nouri

arianouri9@gmail.com

1 Department of Neurosurgery, Geneva University Hospitals, Rue Gabrielle-Perret-Gentil 4, 1205 Geneva, Switzerland

2 University of Geneva, Geneva, Switzerland

3 Department of Neurosurgery, RWTH Aachen University Hospital, Aachen, Germany

4 Department of Neurosurgery, Medical University of Innsbruck, Innsbruck, Austria
5 Department of Neurosurgery, University Clinic for Neurosurgery, Inselspital, Bern, Switzerland

6 Department of Neurosurgery, Charité University Hospital, Berlin, Germany

7 Department of Neurosurgery, Kantonsspital St. Gallen, St. Gallen, Switzerland 


\section{Introduction}

Social media (SoMe) has been developed to connect individuals and groups of similar interest through online communication platforms. Based on World Bank data from 2017 , it was estimated that nearly $50 \%$ of the world population was using the internet [19]. Recently, Facebook reported (March 31, 2020) that monthly active users were 2.60 billion [6], Twitter reported (Q1, 2020) that monetizable daily active users amounted to 166 million [15]. YouTube states on their website that " 2 billion logged-in users visit YouTube each month, and every day people watch over a billion hours of video and generate billions of views" [21], Instagram has around 1 billion active users (as of January 2019 [7], and LinkedIn has over 740 million members [8].

SoMe evolved from chatgroups for adolescents and crude ideas of sharing information and pictures into highly elaborated communication platforms that reach out to the public for the global sharing of information. As with the increased use of SoMe amongst people and organizations, medical health professionals and societies are increasingly adopting these platforms to engage with the general public as well as target audiences $[9,14,18]$. For medical communities, SoMe is used to share scientific publications or breakthroughs or current positions on important topics in the specialized field.

Multiple publications from different medical specialties have highlighted the increased awareness of the medical community to the benefits of SoMe engagement. Indeed, it has been shown that SoMe engagement is related to citations, downloads, Altmetric scores, and Mendeley reads [5, $10,12]$, and it has been specifically reported to be related with academic bibliometric profiles in neurosurgery [3].

The current use of SoMe in Neurosurgery in North America was previously reported, showing that Facebook and Twitter are the most actively used platforms and that private practices dominate the SoMe presence [2]. Recently, it was also shown that there are numerous neurosurgery related Instagram accounts posting images and videos and having a combined following of over 600,000 accounts [20]. However, the use of SoMe in neurosurgery and subsequently its reach are well known in North America, whereas its use in other parts of the world including Europe remains poorly studied. In order to better understand the current landscape of SoMe use in European Neurosurgery, this study sought to investigate the usage of SoMe platforms by neurosurgical centers, journals and neurosurgical organizations amongst member states of the European Association of Neurosurgical Societies (EANS). The aim of the study is to provide an overview of the current state of social media utilization amongst EANS member country institutions.

\section{Methods}

We focused our search strategies on states within the EANS. Neurosurgical journals investigated included those listed on the EANS website and originating in a member state (https:// www.eans.org/page/European_Neurosurgical_Journals). Likewise, European neurosurgical society included those based on the listing of European Member Societies on the EANS website (https://www.eans.org/general/custom.asp? page $=$ societies . In addition to reviewing individual society SoMe usage, multi-national societies within Europe were investigated for SoMe utilization by searching member societies of the World Federation of Neurosurgical Societies (WFNS) (https://www.wfns.org/all-member-societies). For all inquiries, websites were initially screened to find potential SoMe links. Thereafter, the journal or organizational names and abbreviations were searched in the following platforms: Facebook, Twitter, Instagram, and YouTube (search was conducted in June 2020).

Neurosurgery departments within the EANS member countries registered online with EANS (www.eans.org/page/ European_Neurosurgical_Centers) were searched systematically by official institution name and/or their abbreviations for a SoMe account (Twitter, Facebook, and Instagram), and the number of followers/likes/tweets/posts was recorded. The search was conducted with the Google search engine and with the search function of the respective SoMe platforms. Keywords included the English and native language names (where applicable), in addition to the SoMe platform name (search was conducted in May/June, 2021).

For comparison of SoMe activity in North America, the social media activity was recorded for the Congress of Neurological Surgeons (CNS) and the American Association of Neurological Surgeons (AANS), retrieved in Dec., 2020.

For all variables (likes, tweets, followers, etc.) numbers of less than 50 where designated as $<50$. Numbers greater than 50 were rounded down to increments of 50 and designated with a greater than sign (for example 2069 was designated $>2050,320$ was designated $>300$ ).

\section{Results}

\section{Neurosurgery journals}

A total of 16 neurosurgery specific journals were reviewed, including 15 present on the EANS website as well as Acta Neurochirurgica (the EANS affiliated journal) (Table 1). Five of those journals (31\%) had a presence on either Twitter, Facebook, Instagram, or YouTube. None of these were present in all four platforms, but Journal of Neurology, Neurosurgery and Psychiatry (JNNP) and Turkish Neurosurgery 
Table 1 European Neurosurgical Journals as listen by EANS and their current social media utilization

\begin{tabular}{|c|c|c|c|c|c|c|c|c|}
\hline \multirow[t]{2}{*}{ Journal Name } & \multicolumn{2}{|l|}{ Twitter } & \multicolumn{2}{|l|}{ Facebook } & \multicolumn{2}{|l|}{ Instagram } & \multicolumn{2}{|l|}{ Youtube } \\
\hline & Followers & Tweets & Followers & Likes & Followers & Posts & Subscribers & Views \\
\hline Acta Neurochirurgica & $>1950$ & $>400$ & $\mathrm{x}$ & $\mathrm{x}$ & $\mathrm{x}$ & $\mathrm{x}$ & $\mathrm{x}$ & $\mathrm{x}$ \\
\hline British Journal of Neurosurgery & $\mathrm{x}$ & $\mathrm{x}$ & $\mathrm{x}$ & $\mathrm{x}$ & $\mathrm{x}$ & $\mathrm{x}$ & $\mathrm{x}$ & $\mathrm{x}$ \\
\hline Burdenko's Journal of Neurosurgery & $\mathrm{x}$ & $\mathrm{x}$ & $\mathrm{x}$ & $\mathrm{x}$ & $\mathrm{x}$ & $\mathrm{x}$ & $\mathrm{x}$ & $\mathrm{x}$ \\
\hline $\begin{array}{l}\text { Journal of Neurology, Neurosurgery and } \\
\text { Psychiatry }\end{array}$ & $>10,000$ & $>15,900$ & $>23,350$ & $>22,600$ & $\mathrm{x}$ & $\mathrm{x}$ & $>950$ & $>10,250$ \\
\hline Journal of Neurological Sciences & $\mathrm{x}$ & $\mathrm{x}$ & $>950$ & $>900$ & $\mathrm{x}$ & $\mathrm{x}$ & $\mathrm{x}$ & $\mathrm{x}$ \\
\hline Journal of Neurological Surgery Part A & $\mathrm{x}$ & $\mathrm{x}$ & $\mathrm{x}$ & $\mathrm{x}$ & $\mathrm{x}$ & $\mathrm{x}$ & $\mathrm{x}$ & $\mathrm{x}$ \\
\hline Journal of Neurological Surgery Part B & $\mathrm{x}$ & $\mathrm{x}$ & $\mathrm{x}$ & $\mathrm{x}$ & $>2150$ & $>50$ & $>1850$ & $>89,250$ \\
\hline Neurocirugia & $\mathrm{x}$ & $\mathrm{x}$ & $\mathrm{x}$ & $\mathrm{x}$ & $\mathrm{x}$ & $\mathrm{x}$ & $\mathrm{x}$ & $\mathrm{x}$ \\
\hline Neurochirurgie & $\mathrm{x}$ & $\mathrm{x}$ & $\mathrm{x}$ & $\mathrm{x}$ & $\mathrm{x}$ & $\mathrm{x}$ & $\mathrm{x}$ & $\mathrm{x}$ \\
\hline Neurosurgical Review & $\mathrm{x}$ & $\mathrm{x}$ & $\mathrm{x}$ & $\mathrm{x}$ & $\mathrm{x}$ & $\mathrm{x}$ & $\mathrm{x}$ & $\mathrm{x}$ \\
\hline Polish Journal of Neurology and Neurosurgery & $\mathrm{x}$ & $\mathrm{x}$ & $\mathrm{x}$ & $\mathrm{x}$ & $\mathrm{x}$ & $\mathrm{x}$ & $\mathrm{x}$ & $\mathrm{x}$ \\
\hline Romanian Neurosurgery & $\mathrm{x}$ & $\mathrm{x}$ & $\mathrm{x}$ & $\mathrm{x}$ & $\mathrm{x}$ & $\mathrm{x}$ & $\mathrm{x}$ & $\mathrm{x}$ \\
\hline Russian Journal of Neurosurgery & $\mathrm{x}$ & $\mathrm{x}$ & $\mathrm{x}$ & $\mathrm{x}$ & $\mathrm{x}$ & $\mathrm{x}$ & $\mathrm{x}$ & $\mathrm{x}$ \\
\hline Tijdschrift voor Neurologie en Neurochirurgie & $\mathrm{x}$ & $\mathrm{x}$ & $\mathrm{x}$ & $\mathrm{x}$ & $\mathrm{x}$ & $\mathrm{x}$ & $\mathrm{x}$ & $\mathrm{x}$ \\
\hline Turkish Neurosurgery & $>150$ & $>50$ & $<50$ & $<50$ & $>950$ & $>50$ & $\mathrm{x}$ & $\mathrm{x}$ \\
\hline Ukrainian Neurosurgical Journal & $\mathrm{x}$ & $\mathrm{x}$ & $\mathrm{x}$ & $\mathrm{x}$ & $\mathrm{x}$ & $\mathrm{x}$ & $\mathrm{x}$ & $\mathrm{x}$ \\
\hline \multicolumn{9}{|l|}{ By Comparison (retrieved Dec/2020) } \\
\hline Neurosurgery & $>20,800$ & $>1300$ & $>33,900$ & $>32,900$ & $>8700$ & $>700$ & $>7800$ & $>1.4$ million \\
\hline Journal of Neurosurgery (JNS & $>23,400$ & $>8100$ & $>50,600$ & $>48,400$ & $>34,900$ & $>400$ & $\mathrm{x}$ & $\mathrm{x}$ \\
\hline
\end{tabular}

had a presence in 3 platforms each. Twitter and Facebook were each used by 3 journals and Instagram and YouTube by 2 journals. The highest number of followers, likes, and tweets was reported for JNNP, and Journal of Neurological Surgery Part B (Skull Base) had the most subscribers and video views.

The journals of CNS (Neurosurgery) and AANS (Journal of Neurosurgery) in comparison had a significant presence and user engagement on multiple SoMe platforms, with the highest use evident on Facebook ( $>48,400$ followers for JNS and $>32,900$ followers for Neurosurgery), and a high number of YouTube videos for CNS videos ( $>1.4$ million).

\section{National and multi-national European neurosurgical societies}

A total of 39 country societies listed on EANS, and 3 multi-national societies (including EANS) were assessed for SoMe usage (Table 2). SoMe usage was identified for 11 national $(28.2 \%)$ and 2 multi-national neurosurgical societies. The most commonly used platforms were Facebook (11 accounts, 28.2\%) and Twitter (5 accounts $12.8 \%$ ). There was only 1 Instagram account found $(2.6 \%)$ and 2 YouTube accounts (5.1\%). All societies which had Twitter accounts also had a Facebook account. The French Society of Neurosurgery had the largest number of Facebook followers $(>2800)$ and Likes ( $>2700)$, followed by the Hellenic
Neurosurgical Society with ( $>1800$ follows, $>1800$ Likes). All other Facebook accounts had less than 1000 followers. The Society of British Neurological Surgeons had the largest number of Twitter followers $(>2850)$ followed by the Spanish Society of Neurosurgery $(>450)$.

In terms of multi-national societies, EANS utilized both Twitter and Facebook accounts and had the most followers with $>5100$ and $>5450$, respectively. The Scandinavian Society had a Facebook account. No account associated with Southeast Europe Neurosurgical Society was found.

\section{EANS neurosurgical centers}

At the time of the search, a total of 1000 centers were listed on the EANS website (Table 3). A total of 87 SoMe accounts were found on either Facebook, Instagram, or Twitter, for 64 centers (SoMe use of 6.4\%) in 22 different countries (55\% of countries, 40 countries). Of these $67 \%$ $(n=43 / 64)$ arose from 6 countries (England, Germany, Italy, Romania, Turkey, Ukraine). There were more Facebook accounts $(n=42)$ than Instagram accounts $(n=23)$ or Twitter accounts $(n=22)$. England and Turkey had the most EANS affiliated centers with a SoMe presence $(n=9)$. The Brain Institute in Romania had the largest number of Facebook Followers (>17,500), and National Center for Neurosurgery in Kazakhstan had the highest number of Instagram followers $(20,500)$, whereas the 2 most active twitter 
Table 2 State and multi-national societies and their current use of social media

\begin{tabular}{|c|c|c|c|c|c|c|}
\hline Twitter & & Facebook & & Instagram & & YouTube \\
\hline ollowers & Tweets & Followers & Likes & Followers & Posts & Subscribers \\
\hline
\end{tabular}

National societies

Albanian Neurosurgical Society

Armenian Neurosurgical Association

Austrian Society of Neurosurgery

Association of Neurosurgeons in Bosnia and Herzegovina $\mathrm{x}$

Association of Russian Neurosurgeons

Belgian Society of Neurosurgery

Bulgarian Society of Neurosurgery

Croatian Neurosurgical Society

Cyprus Neurosurgical Society

Czech Neurosurgical Society

Danish Neurosurgical Society

Dutch Association of Neurosurgeons

Estonian Neurosurgical Society

Finnish Neurosurgical Society

French Society of Neurosurgery

German Society for Neurosurgery

Hellenic Neurosurgical Society

Hungarian Neurosurgical Society

Israel Neurosurgical Society

Italian Neurosurgical Society

Kazakh Association of Neurosurgeons

Kosovo Neurosurgical Society

Latvian Association of Neurosurgeons

Lithuanian Neurosurgical Society

Macedonian Association of Neurosurgeons

Moldova Association of Neurosurgeons

Norwegian Neurosurgical Association

Polish Society of Neurosurgeons

Portuguese Neurosurgery Society

Romania Society of Neurosurgery

Serbian Neurosurgical Society

Slovak Neurosurgical Society

Slovenian Neurosurgical Society

Society of British Neurological Surgeons

Spanish Society of Neurosurgery

Swedish Neurosurgical Society

Swiss Society of Neurosurgery

Turkish Neurosurgical Society

Ukrainian Association of Neurosurgeons

Multi-national societies

Scandinavian Neurosurgical Society

Southeast Europe Neurosurgical Society

European Association of Neurosurgical Societies

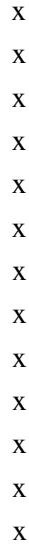

$<100$

$\mathrm{X}$

$<100$

$\mathrm{X}$

$\mathrm{X}$

$\mathrm{X}$

$>2850$

$>450$

$\mathrm{x}$

$\mathrm{X}$

$>150>50>850$

$\mathrm{x} \quad \mathrm{X} \quad>500$

$\begin{array}{lllll}\mathrm{X} & \mathrm{X} & >100 & >100 & \mathrm{x} \\ \mathrm{x} & \mathrm{x} & \mathrm{x} & \mathrm{x} & \mathrm{x} \\ >5100 & >2450 & >5450 & >5300 & \mathrm{x}\end{array}$

X X X

$\mathrm{X}$

$\mathrm{X}$

$\mathrm{X}$

$\mathrm{X}$

$\mathrm{X}$

$\mathrm{X}$

$\mathrm{X}$

$\mathrm{X}$

$\mathrm{X}$

$\mathrm{X}$

$\mathrm{X}$

$\mathrm{X}$

$\mathrm{X}$

$\mathrm{X}$ accounts were located in England: King's College Neurosurgery ( $>3600$ followers) and The Royal London Hospital Neurosurgery ( $>3500) .17$ departments used more than one SoMe platform, and 6 used all 3 SoMe platforms. One department, Klinik für Neurochirurgie, UKSH (Universitätsklinikum Schleswig-Holstein Hochleistungsmedizin) had 2 
Table 3 EANS neurosurgical centers

Neurosurgical centers

Facebook Instagram

Followers Followers Posts Followers Tweets

General Hospital Damiaan (Belgium)

Heart and Brain Center of Clinical Excellence (Bulgaria)

Clinical Hospital KB Dubrava (Croatia)

University Hospital Kralovske Vinohrady (Czech Republic)

RLH Neurosurgery (England)

UHB Neurosurgery (England)

King's Neurosurgery (England)

Preston Neurosurgery (England)

UHP Neurosurgery (England)

Leeds Neurosurgery (England)

St. George's Neuro (England)

Great Ormond Street Neurosurgery (England)

Wessex Neurological Centre, Department of Neurosurgery (England)

International Neuroscience Institute (INI), Hanover (Germany)

University Hospital and Faculty of Medicine, Eberhard Karls University Tübingen (Germany)

Klinik für Neurochirurgie UKSH (Germany)*

Department of Neurosurgery UKSH (Germany)*

Neurosurgery, TU Munich (Germany)

Neurochirurgie-Universitätsmedizin Göttingen (Germany)

General Military Hospital of Thessaloniki (Greece)

Szent János Hospital (Hungary)

Neurosurgery Budapest (Hungary)

University Hospital Policlinico Paolo Giaccone (Italy)

Policlinico A. Gemelli, Roma (Italy)

Policlinico Tor Vergata, Roma (Italy)

Neurosurgery Division, Dip. Neuroscience and Rehabilitation, Arcispedale S. Anna Cona, Ferrara (Italy)

U.O.C. Neurosurgery, Hospital S. Maria Goretti, Latina (Italy)

Mater Olbia Hospital-Qatar Foundation Endowment and Gemelli Foundation (Italy)

Hospital Santo Spirito (Italy)

Verona (Italy)

Hospital Uni. Del Rocio (Italy)

National Center for Neurosurgery (Kazakhstan)

Institute Of Neurology and Neurosurgery (Moldova)

Clinical Republican Hospital (Moldova)

Department of Public Neurosurgery, Independent Healthcare Center, Voivodship Medical Center (Poland)

Emergency Clinical Hospital “Bagdasar-Arseni”, Bucuresti I (Romania)

Neurohope (Romania)

Brain Institute (Romania)

County Emergency Hospital, Tg. Mures (Romania)

County Emergency Hospital "Pius Brinzeu", Timisoara (Romania)

National Medical Research Center for Neurosurgery named after Academician N.N. Burdenko (Russia)

Federal State Budgetary Institution, Federal Neurosurgical Center (Russia)

Centro Medico Asturias (Spain)

Neurosurgical Clinic, Skåne University Hospital (Sweden)

Neurochirurgie LUMC (The Netherlands)

\begin{tabular}{|c|c|c|c|c|}
\hline$>5200$ & $\mathrm{x}$ & $\mathrm{x}$ & $\mathrm{x}$ & $\mathrm{x}$ \\
\hline$>500$ & $\mathrm{x}$ & $\mathrm{x}$ & $\mathrm{x}$ & $\mathrm{x}$ \\
\hline$>650$ & $\mathrm{x}$ & $\mathrm{x}$ & $\mathrm{x}$ & $\mathrm{x}$ \\
\hline$>850$ & $\mathrm{x}$ & $\mathrm{x}$ & $\mathrm{x}$ & $\mathrm{x}$ \\
\hline $\mathrm{x}$ & $\mathrm{x}$ & $\mathrm{x}$ & $>3500$ & $>400$ \\
\hline $\mathrm{x}$ & $\mathrm{x}$ & $\mathrm{x}$ & $>600$ & $>100$ \\
\hline$>1300$ & $>350$ & $>50$ & $>3600$ & $>1500$ \\
\hline $\mathrm{x}$ & $\mathrm{x}$ & $\mathrm{x}$ & $>600$ & $>150$ \\
\hline $\mathrm{x}$ & $\mathrm{x}$ & $\mathrm{x}$ & $>100$ & $<50$ \\
\hline$>500$ & $\mathrm{x}$ & $\mathrm{x}$ & $>1000$ & $>700$ \\
\hline$>300$ & $\mathrm{x}$ & $\mathrm{x}$ & $>300$ & $>100$ \\
\hline $\mathrm{x}$ & $\mathrm{x}$ & $\mathrm{x}$ & $>1400$ & $>200$ \\
\hline$>100$ & $\mathrm{x}$ & $\mathrm{x}$ & $>400$ & $>200$ \\
\hline$>250$ & $\mathrm{x}$ & $\mathrm{x}$ & $\mathrm{x}$ & $\mathrm{x}$ \\
\hline$<50$ & $\mathrm{x}$ & $\mathrm{x}$ & $\mathrm{x}$ & $\mathrm{x}$ \\
\hline $\mathrm{x}$ & $>100$ & $<50$ & $\mathrm{x}$ & $\mathrm{x}$ \\
\hline $\mathrm{x}$ & $\mathrm{x}$ & $\mathrm{x}$ & $>50$ & $<50$ \\
\hline $\mathrm{x}$ & $\mathrm{x}$ & $\mathrm{x}$ & $>400$ & $>150$ \\
\hline $\mathrm{x}$ & $\mathrm{x}$ & $\mathrm{x}$ & $>50$ & $<50$ \\
\hline$>750$ & $\mathrm{x}$ & $\mathrm{x}$ & $\mathrm{x}$ & $\mathrm{x}$ \\
\hline$>200$ & $\mathrm{x}$ & $\mathrm{x}$ & $\mathrm{x}$ & $\mathrm{x}$ \\
\hline$>200$ & $>1000$ & $<50$ & $\mathrm{x}$ & $\mathrm{x}$ \\
\hline$>1300$ & $\mathrm{x}$ & $\mathrm{x}$ & $\mathrm{x}$ & $\mathrm{x}$ \\
\hline$>2500$ & $\mathrm{x}$ & $\mathrm{x}$ & $\mathrm{x}$ & $\mathrm{x}$ \\
\hline$<50$ & $\mathrm{x}$ & $\mathrm{x}$ & $\mathrm{x}$ & $\mathrm{x}$ \\
\hline $\mathrm{x}$ & $>100$ & $<50$ & $\mathrm{x}$ & $\mathrm{x}$ \\
\hline $\mathrm{x}$ & $>100$ & $<50$ & $\mathrm{x}$ & $\mathrm{x}$ \\
\hline $\mathrm{x}$ & $>50$ & $>200$ & $\mathrm{x}$ & $\mathrm{x}$ \\
\hline $\mathrm{x}$ & $>100$ & $<50$ & $\mathrm{x}$ & $\mathrm{x}$ \\
\hline $\mathrm{x}$ & $<50$ & $<50$ & $\mathrm{x}$ & $\mathrm{x}$ \\
\hline $\mathrm{x}$ & $>200$ & $<50$ & $>400$ & $>100$ \\
\hline$>3800$ & $>20,500$ & $>500$ & $>150$ & $>800$ \\
\hline$>3700$ & $>100$ & $<50$ & $\mathrm{x}$ & $\mathrm{x}$ \\
\hline$>1400$ & $\mathrm{x}$ & $\mathrm{x}$ & $\mathrm{x}$ & $\mathrm{x}$ \\
\hline$>1300$ & $\mathrm{x}$ & $\mathrm{x}$ & $\mathrm{x}$ & $\mathrm{x}$ \\
\hline$>350$ & $\mathrm{x}$ & $\mathrm{x}$ & $\mathrm{x}$ & $\mathrm{x}$ \\
\hline$>3800$ & $>200$ & $<50$ & $>50$ & $<50$ \\
\hline$>17,500$ & $>800$ & $<100$ & $<50$ & $>350$ \\
\hline$>600$ & $\mathrm{x}$ & $\mathrm{x}$ & $\mathrm{x}$ & $\mathrm{x}$ \\
\hline$>2400$ & $\mathrm{x}$ & $\mathrm{x}$ & $\mathrm{x}$ & $\mathrm{x}$ \\
\hline$>2700$ & $>7300$ & $>300$ & $<50$ & $>150$ \\
\hline$>350$ & $\mathrm{x}$ & $\mathrm{x}$ & $\mathrm{x}$ & $\mathrm{x}$ \\
\hline$>1600$ & $>450$ & $>100$ & $>350$ & $>550$ \\
\hline$<50$ & $\mathrm{x}$ & $\mathrm{x}$ & $\mathrm{x}$ & $\mathrm{x}$ \\
\hline $\mathrm{x}$ & $\mathrm{x}$ & $\mathrm{x}$ & $>50$ & $<50$ \\
\hline
\end{tabular}


Table 3 (continued)

\begin{tabular}{|c|c|c|c|c|c|}
\hline \multirow[t]{2}{*}{ Neurosurgical centers } & \multirow{2}{*}{$\begin{array}{l}\text { Facebook } \\
\text { Followers }\end{array}$} & \multicolumn{2}{|l|}{ Instagram } & \multicolumn{2}{|l|}{ Twitter } \\
\hline & & Followers & Posts & Followers & Tweets \\
\hline Neurologie/Neurochirurgie UMCU (The Netherlands) & $\mathrm{x}$ & $>700$ & $<100$ & $\mathrm{x}$ & $\mathrm{x}$ \\
\hline Lokman Hekim University, Faculty of Medicine, Department of Neurosurgery (Turkey) & $<50$ & $>2200$ & $>200$ & $\mathrm{x}$ & $\mathrm{x}$ \\
\hline Bursa Acibadem Hospital, Department of Neurosurgery (Turkey) & $<50$ & $\mathrm{x}$ & $\mathrm{x}$ & $\mathrm{x}$ & $\mathrm{x}$ \\
\hline Pamukkale University Hospitals, Department of Neurosurgery (Turkey) & $<50$ & $>1700$ & $>150$ & $\mathrm{x}$ & $\mathrm{x}$ \\
\hline Eskisehir State Hospital, Department of Neurosurgery (Turkey) & $>300$ & $\mathrm{x}$ & $\mathrm{x}$ & $\mathrm{x}$ & $\mathrm{x}$ \\
\hline $\begin{array}{l}\text { Haydarpasa Numune Training and Research Hospital, Department of Neurosurgery (Tur- } \\
\text { key) }\end{array}$ & $<50$ & $\mathrm{x}$ & $\mathrm{x}$ & $\mathrm{x}$ & $\mathrm{x}$ \\
\hline Vm Medical Park Samsun Hastanesi (Turkey) & $>2500$ & $\mathrm{x}$ & $\mathrm{x}$ & $\mathrm{x}$ & $\mathrm{x}$ \\
\hline Istanbul Medeniyet University, Faculty of Medicine, Department of Neurosurgery (Turkey) & $\mathrm{x}$ & $>450$ & $>200$ & $\mathrm{x}$ & $\mathrm{x}$ \\
\hline Osmangazi University, Department of Neurosurgery (Turkey) & $\mathrm{x}$ & $>200$ & $>100$ & $\mathrm{x}$ & $\mathrm{x}$ \\
\hline ITF Beyin ve Sinir Cerrahisi (Turkey) & $\mathrm{x}$ & $>500$ & $<50$ & $\mathrm{x}$ & $\mathrm{x}$ \\
\hline $\begin{array}{l}\text { Dnipro Regional Clinical Hospital Named After I.I.Mechnikov Neurosurgical Department } \\
\text { (Ukraine) }\end{array}$ & $>1200$ & $\mathrm{x}$ & $\mathrm{x}$ & $\mathrm{x}$ & $\mathrm{x}$ \\
\hline Kharkiv City Clinical Hospital №7, Neurosurgical Department (Ukraine) & $>1200$ & $>100$ & $<50$ & $\mathrm{x}$ & $\mathrm{x}$ \\
\hline $\begin{array}{l}\text { Romodanov Neurosurgery Institute, National Academy of Medical Sciences of Ukraine, } \\
\text { Neurosurgical Department (Ukraine) }\end{array}$ & $>2800$ & $\mathrm{x}$ & $\mathrm{x}$ & $\mathrm{x}$ & $\mathrm{x}$ \\
\hline Kyiv City Center for Pediatric Neurosurgery (Ukraine) & $>450$ & $\mathrm{x}$ & $\mathrm{x}$ & $\mathrm{x}$ & $\mathrm{x}$ \\
\hline International Neurosurgical Center (Ukraine) & $>5700$ & $\mathrm{x}$ & $\mathrm{x}$ & $\mathrm{x}$ & $\mathrm{x}$ \\
\hline Odessa Regional Clinical Hospital, Neurosurgical Department (Ukraine) & $<50$ & $\mathrm{x}$ & $\mathrm{x}$ & $\mathrm{x}$ & $\mathrm{x}$ \\
\hline MSN Neurosurgery (Scotland) & $\mathrm{x}$ & $\mathrm{x}$ & $\mathrm{x}$ & $>150$ & $<50$ \\
\hline INS Neurosurgery (Scotland) & $\mathrm{x}$ & $\mathrm{x}$ & $\mathrm{x}$ & $>1400$ & $>950$ \\
\hline Geneva Neurosurgery (Switzerland) & $\mathrm{x}$ & $>350$ & $<50$ & $>250$ & $<100$ \\
\hline University Hospital of Wales, Department of Neurosurgery (Wales) & $>50$ & $\mathrm{x}$ & $\mathrm{x}$ & $\mathrm{x}$ & $\mathrm{x}$ \\
\hline Total & 42 & 23 & & 22 & \\
\hline
\end{tabular}

*Same clinical department (accounts in different language)

accounts one with slightly different names: 1 Twitter account in English and 1 German account for Instagram.

\section{Discussion}

\section{The state of SoMe in neurosurgery in Europe}

The results of our research show that European SoMe use from an institutional standpoint remains low, with only $6.4 \%$ of neurosurgical centers listed on the EANS website having a SoMe presence. Furthermore, while SoMe presence occurred amongst approximately half (55\%) of the affiliated countries, two-thirds of SoMe accounts originated from only 6 countries. Part of the reason for this discrepancy is possibly due to the fact that the English language dominates many of the platforms such as Twitter [4]. This is supported by the fact that the 2 most followed neurosurgery center Twitter accounts (King's Neurosurgery and RLH Neurosurgery), the most followed national society (Society of British Neurological Surgeons), and the most followed journal (JNNP) all originate in England. However, strong SoMe engagement was also seen sporadically in other European countries. For example, the Brain Institute in Romania had a following of over 17,500 on Facebook, and the National Center for Neurosurgery in Kazakhstan had the highest number of Instagram followers (20,500). Additionally, the French, Hellenic, and Turkish neurosurgery societies had over 2800, 1800, and 850 followers on Facebook, respectively.

It appears from these results that the utilization of SoMe in Europe is much lower than in North America. In 2016, Alotaibi et al. [3] showed that $18.4 \%$ of neurosurgical programs in North America had an affiliated social media account, representing almost a threefold higher adoption 5 years ago. However, this list of programs was limited to academic training programs accredited by ACGME and RCPSC and may therefore not be directly comparable to the list of centers listed on the EANS website.

While language may be a factor limiting the adoption of social media in non-English native speaking countries, other reasons for the discrepancy between North America and Europe may involve concerns regarding privacy and general differences in SoMe culture, as well as less interest from a "marketing" point of view considering differences in health care systems. Laws and regulations such as (HIPAA/GDPR) 
between countries may also play a role in the capacity of SoMe adoption due to potential content restrictions and legal liability. Besides these possibilities, it is also plausible that SoMe usage differs considerably in Europe amongst individuals and organizations, with elevated SoMe presence potentially amongst individuals, however, this has not been thoroughly investigated. Ultimately, the lack of SoMe engagements from academic programs in Europe is probably due to multiple factors: they require resources, time, competence, high language proficiency, and a SoMe strategy. Neurosurgery departments, unlike most other specialties, typically comprised a small team, and therefore this may be part of the problem; however, the increased utilization of SoMe in North American neurosurgery programs [2] indicates that some form of SoMe presence is achievable.

In terms of neurosurgical journals, besides JNNP, Acta Neurochirugica, the Journal of Neurological Sciences and Journal of Neurological Surgery Part B also had active SoMe presence. In particular Journal of Neurological Surgery Part $B$ had one of only 2 accounts found on YouTube, and had a relatively large subscriber base and nearly 90,000 views.

\section{The increasing adoption and importance of SoMe}

Studies from various specialties have shown that social media engagement correlated in improved exposure of research work and can influence citations [3, 16, 18]. Direct evidence of this impact was recently supported by a randomized trial which assessed the impact of tweeting or not tweeting, on citations and Almetric score at 1 year, showing that independent predictors of citations included tweeting and exposure to a larger number of Twitter followers [10].

Use of SoMe remains diverse, forms the perspective of patients and neurosurgeons, and from the perspective of geography, and social media platforms. This is exemplified by a recent systematic review of social media in neurosurgery which showed that patients and caregivers most commonly used Facebook and Twitter, whereas nearly $50 \%$ of neurosurgeons used LinkedIn and Doximity [13].

While it has become well accepted that SoMe engagement provides multiple beneficial benefits to organizations, by way of branding, public engagement, promoting research and information dissemination, the recent COVID pandemic has also shown that a SoMe presence is critical in continuing conversations between organizations and their stakeholders during times of crises. The cancellations of congresses and changes to online formats including webinars or virtual meetings such as the EANS 2020 meeting (www.eans.org/page/EANS2020_Congress), have demonstrated how critical SoMe use can be. SoMe use during such congresses does not only allow for promoting such events but also is used for Q\&A (question and answer) sessions for live presentations. Likewise, COVID-19 also has changed the neurosurgery residency matching process in the USA which normally involves many in-person interviews by candidates who fly across the country and which have been largely changed to video interviews [1]. As a consequence of this, it has been notable that neurosurgery residency programs have made use of their SoMe accounts to engage with potential candidates.

It is important to note that social media provides many potential benefits, but also can bring challenges once they become highly integrated and present with a large following. A large SoMe following may result in increased communication with the institution from the neurosurgery community, patients, and activists, which will require active moderating. Management of this may eventually require input from a media relations team, often from the hospital.

\section{Opportunities and steps that can be taken to bridge the SoMe gap}

There appears to be growing evidence that there are benefits of SoMe for neurosurgery, and it is evident that from a European point of view, further work is necessary to integrate this into our specialty. The EANS, serving as the principal vehicle for association among the various neurosurgical stakeholders, is uniquely positioned to encourage such a transition. Tools for building a SoMe profile have been developed by Neurosurgery Research and Education Fund and may help those interested in creating a SoMe account (Twitter) [11]. While the EANS is increasingly engaging on SoMe platforms, the CNS and AANS have about double and triple the number of followers on Twitter, respectively, which indicated that further growth is possible.

As SoMe in neurosurgery is further developed in Europe, it will also be important to take into consideration areas in particular need of improvement. It has been recently highlighted that dissemination of content via SoMe in the form of videos remains poor, and is an area which could benefit from particular attention $[13,17]$.

Ultimately, the lack of SoMe adoption indicates that there is an opportunity for growth in this area. Depending on the situation, including financial, human resources and size of the country, efforts can be made to optimize a SoMe strategy. For example, larger institutions may benefit from individualized accounts, whereas smaller institutions could seek to develop their neurosurgical society SoMe presence, as this remains an area of need in development as well. Increased, SoMe development can facilitate communication of neurosurgical departments, particularly smaller ones, with a global audience. 


\section{Limitations}

As SoMe usage changes on a daily basis, the number of followers as well as other SoMe parameters may differ from those reported. Additionally, since the search and writing of this paper, it is possible that new accounts have been created which are not included in the present paper. It is also possible that some accounts were missed, despite attempts to find all relevant accounts. However, it is likely that those accounts are either not actively used or do not yet have significant SoMe activity. The search of SoMe accounts for neurosurgery departments was limited to Twitter, Instagram, and Facebook as these are typically more commonly used for larger audiences. LinkedIn is a popular SoMe platform; however, it was not assessed for a number of reasons: (1) principally used by individuals and not departments, (2) profiles may be public or private, (3) usage is typically for connecting with individuals rather than dissemination openly to wide audiences, (4) the large number of profiles would make it unfeasible to accurately assess LinkedIn usage.

\section{Conclusion}

The use of SoMe in neurosurgery in Europe is limited, and no accounts were found in most countries with some notable exceptions. Likewise, SoMe use remains sparse among European neurosurgery journals. Given that SoMe has been seen as an important tool to engage with patients and to correlate with effective dissemination of academic production in other specialties as well as neurosurgery within North America, a concerted effort should be made to promote its uptake among EANS member states.

Acknowledgements We would like to acknowledge the help of Ivan Gusic, Fabio Bouras, and Kor-Gaël Toruslu in the data collection.

Funding Open Access funding provided by Université de Genève.

\section{Declarations}

Research involving human participants and/or animals The research did not involve humans or animal participants.

Informed consent There was no informed consent required as this research did not involve humans.

Conflict of interest The authors declare no competing interests.

Open Access This article is licensed under a Creative Commons Attribution 4.0 International License, which permits use, sharing, adaptation, distribution and reproduction in any medium or format, as long as you give appropriate credit to the original author(s) and the source, provide a link to the Creative Commons licence, and indicate if changes were made. The images or other third party material in this article are included in the article's Creative Commons licence, unless indicated otherwise in a credit line to the material. If material is not included in the article's Creative Commons licence and your intended use is not permitted by statutory regulation or exceeds the permitted use, you will need to obtain permission directly from the copyright holder. To view a copy of this licence, visit http://creativecommons.org/licenses/by/4.0/.

\section{References}

1. AAMC (2020) Conducting interviews during the coronavirus pandemic. www.aamc.org/what-we-do/mission-areas/medicaleducation/conducting-interviews-during-coronavirus-pandemic.

2. Alotaibi NM, Badhiwala JH, Nassiri F, Guha D, Ibrahim GM, Shamji MF, Lozano AM (2016) The current use of social media in neurosurgery. World neurosurgery 88(e617):619-624

3. Alotaibi NM, Guha D, Fallah A, Aldakkan A, Nassiri F, Badhiwala JH, Ibrahim GM, Shamji MF, Macdonald RL, Lozano AM (2016) Social media metrics and bibliometric profiles of neurosurgical departments and journals: is there a relationship? World neurosurgery 90(e577):574-579

4. Alshaabi T, Dewhurst DR, Minot JR, Arnold MV, Adams JL, Danforth CM, Dodds PS (2020) The growing echo chamber of social media: measuring temporal and social contagion dynamics for over 150 languages on Twitter for 2009--2020. arXiv preprintarXiv:200303667

5. Botting N, Dipper L, Hilari K (2017) The effect of social media promotion on academic article uptake. J Am Soc Inf Sci 68:795-800

6. Facebook (2020) Facebook reports first quarter 2020 results.

7. Kocak E, Nasir VA, Turker HB (2020) What drives Instagram usage? User motives and personality traits. Online Information Review

8. LinkedIn (2021) About LinkedIn. https://about.linkedin.com/. Accessed 29.03.2021

9. Loeb S, Bayne CE, Frey C, Davies BJ, Averch TD, Woo HH, Stork B, Cooperberg MR, Eggener SE, Group AUASMW (2014) Use of social media in urology: data from the American Urological A ssociation (AUA). BJU Int 113:993-998

10. Luc JG, Archer MA, Arora RC, Bender EM, Blitz A, Cooke DT, Hlci TN, Kidane B, Ouzounian M, Varghese TK Jr (2021) Does tweeting improve citations? One-year results from the TSSMN prospective randomized trial. Ann Thorac Surg 111:296-300

11. NREF (2020) NREF and Young neurosurgeons join forces to launch social media lab. https://www.nref.org/en/NREF-inAction/News-Updates/Enews-March-2020/NREF-and-YoungNeurosurgeons-Join-Forces-to-Launch-Social-Media-Lab?utm_ source=email\&utm_medium =email\&utm_campaign $=$ email\&_ $\mathrm{zs}=\mathrm{tK} 7 \mathrm{Ke} 1 \& \_\mathrm{zl}=\mathrm{sXEe} 6$

12. Peoples BK, Midway SR, Sackett D, Lynch A, Cooney PB (2016) Twitter predicts citation rates of ecological research. PloS one 11(11):e0166570

13. Shlobin NA, Hoffman SC, Clark JR, Hopkins BS, Kesavabhotla K, Dahdaleh NS (2021) Social Media in neurosurgery: a systematic review. World neurosurgery

14. Steele SR, Arshad S, Bush R, Dasani S, Cologne K, Bleier JI, Raphaeli T, Kelz RR (2015) Social media is a necessary component of surgery practice. Surgery 158:857-862

15. Twitter (2020) Q1 2020 Shareholder Letter.

16. Wang J, Alotaibi NM, Ibrahim GM, Kulkarni AV, Lozano AM (2017) The spectrum of altmetrics in neurosurgery: the top 100 
"trending" articles in neurosurgical journals. World neurosurgery 103(e881):883-895

17. Ward M, Ward B, Abraham M, Nicheporuck A, Elkattawy O, Herschman Y, Mammis A, Liu JK, Paskhover B (2019) The educational quality of neurosurgical resources on YouTube. World neurosurgery 130:e660-e665

18. Wexner S, Petrucci A, Brady R, Ennis-O'Connor M, Fitzgerald J, Mayol J (2017) Social media in colorectal surgery. Colorectal Dis 19:105-114

19. WorldBank (2017) Individuals using the internet (\% of population).
20. Yakar F, Jacobs R, Agarwal N (2020) The current usage of Instagram in neurosurgery. Interdisciplinary Neurosurgery 19:100553

21. YouTube-Official-Blog (2021) YouTube. https://blog.youtube/ press. Accessed 29.03.2021

Publisher's note Springer Nature remains neutral with regard to jurisdictional claims in published maps and institutional affiliations. 